\title{
Патологический разум в пьесе Аси Волошиной Пациенты
}

\author{
Pathological reason in Asya Voloshina's drama Patients
}

\begin{abstract}
In this article Asia Voloshina's drama Patients is analysed in the context of the pathologies the characters deal with. The inspirations of her play are described, i.e. the films and memories of Luis Buñuel as well as medical cases from the practice of Oliver Sacks. The author also refers to Dante Alighieri's The Divine Comedy. In this perspective the analysed work is a text about fear that appears when the quest for freedom is abandoned. If in The Divine Comedy in hell and purgatory are people who are sinful and do not know Christ, in the universe of the clinic in "hell" there are all those who are afraid. Voloshina's play constitutes one out of a number of her works concerning the social and political situation in Russia. In the play, the author points to fear as the source of the viciousness of the collective consciousness. Voloshina raises a question that is characteristic of the post-Soviet space: the characters "hide from themselves and their fate". Voloshina, however, leads them towards it.
\end{abstract}

Keywords: contemporary theatre, philosophy, neurology, Oliver Sacks, Luis Buñuel

Krzysztof Tyczko, Uniwersytet im. Adama Mickiewicza w Poznaniu, Poznań - Polska, krzysztof.tyczko@amu.edu.pl, ORCID ID: https://orcid.org/0000-0002-8926-9641

Ася Волошина родилась в 1985 году в Ростове-на-Дону. Двадцать восемь лет спустя она окончила магистратуру по специальности драматургия в Российском государственном институте сценических искусств (курс Натальи Скороход). По состоянию на сегодняшний день Волошина является автором более двадцати пьес, последние из которых это Дания тюрьма и Подтвердите, что вы человек.

Для творчества Волошиной характерно философское размышление о состоянии человека и мира. Сосредоточиваясь на истории конкретного человека, Волошина одновременно ведет обобщенное повествование о боли, страдании, смерти, свободе, рабстве, справедливости и жертвенности. Кроме того, с каждым новым текстом она все очевиднее подвергает критике текущую общественно-политическую ситуацию в России, не только фокусируясь на представителях власти, но анализируя географические, культурные и социальные составляющие происходящего. Драматургу небезразличен 
также вопрос о моральной силе молодого поколения и его способностях влиять на российскую действительность.

Пьесы Волошиной переведены на несколько языков: французский, английский и польский. В 2015 году в Театре „Вспулчесны” во Вроцлаве состоялась премьера спектакля Не надо (реж. Камила Михаляк, перевод Татьяны Джицимской). На польский язык была также переведена пьеса Анна Франк (перевод Ежи Сыгидуса) и монопьеса Мама (перевод Кшиштофа Тычко, публикация в ежемесячнике „Dialog” 2018, № 3), перформативное чтение которой состоялось 28 мая 2018 года в рамках 14-го Международного театрального фестиваля „Контакт” в Торуне (реж. Филип Фронтчак). На польский язык переведена также пьеса Паииенты (перевод Кшиштофа Тычко).

Современной трактовке понятия разума толчок дала философия Иммануила Канта. Разуму, понимаемому в качестве единой функции открытия и познания заложенных Абсолютом рациональных начал, Кант противопоставил плюрализм разумов как продуктов культуры и действующего в ее рамках человека. Познание вещчи в себе, некой абстрактной сущности, оказалось невозможным из-за ограниченности человеческого разума и его раздробленности. Человеку приходится довольствоваться лишь представлениями о явлениях. Разум, как отмечает Эдмунд Моравец, был поделен на разные „частичные функции и специфические действия, что, собственно, и привело к ограничению теоретического разума и выдвижению на первое место практического разума" [здесь и далее перевод мой - К. Т.] (Morawiec 131). „Человек, - пишет далее польский философ, - неспособен познать существование Бога и интеллигибельного мира, поэтому нельзя его воспринимать как животное, способное создавать метафизику" (Morawiec 131).

Современные концепции разума, согласно философу, направлены уже не на природу человека, а на его действия. Разум в наше время является неким условным центром, в котором происходят процессы многостороннего взаимодействия с реальностью. „Разум стал процедурой” и потерял метафизический статус естественного, врожденного, зато человек приобрел статус мыслящей и действующей личности (Morawiec 147).

*

Действие Пациентов (2015) происходит в клинике для людей с неврологическими отклонениями. Пациенты страдают болезнями, подробно описанными британским неврологом Оливером Саксом в книге Человек, который принял жену за шляпу, и другие истории из врачебной практики (The Man Who Mistook His Wife for a Hat, 1985). Но кроме отсылки к британ- 
скому врачу, Волошина в качестве второй опоры своего художественного мира выбрала жизнь и творчество испанского режиссера Луиса Бунюэля, работавшего в основном в стиле сюрреализма и известного как скандалиста и критика социальных устоев. Герои Бунюэля постоянно попадают в обстоятельства с разрушенной причинно-следственной связью. Сопровождая свои действия умными комментариями, они с серьезным лицом совершают очевидные нелепости. Для фильмов испанского режиссера характерен также шок, которому подвергается зритель, и здесь речь идет не только о его ранних фильмах, например об Андалузском nce (Un Chien Andalou, 1928), с реалистичным кадром разрезания глаза, но также о внушительном изображении Девы Марии в Млечном nymu (La Voie Lactée, 1969) как очень привлекательной молодой девушки, которая, по всей вероятности, вовсе не старше своего сына, а то и моложе его. Ее образ не оставляет сомнений в том, что режиссер балансирует на грани социального приличия. Данные нарушения нормы, вошедшие в художественный мир Волошиной, я и называю патологическим разумом - процедурой, движущей универсум пьесы к финалу, т. е. к показу фильма, снятого одним из героев, разрушению и высвобождению „забытого” в героях.

В пьесе семь персонажей: Ион - кинорежиссер, Агнешка - молодая религиозная полька, Маша - молодая женщина из России, Штурмберг - западноевропейский интеллектуал и бывший врач, Миссис О’Нилл - пожилая женщина и Джонни - пожилой мужчина, в прошлом моряк. Язык общения героев - русский. В числе персонажей упоминается также доктор Проспер главный врач клиники, в прошлом ученик Штурмберга, вступивший в должность с момента ухода учителя. Его внесценический статус охарактеризован автором как символ богооставленности. Семантика произведения, таким образом, выходит за рамки интертекстуальной игры с научными и художественными мирами Сакса и Бунюэля и становится транспозицией неких онтологических идей в художественное повествование.

„Пациенты”- пьеса не о болезнях, не о здоровье и не о норме (и даже не о ее отсутствии). Она о том, как герои волей или неволей прячутся от себя и своей судьбы. И на этой кружной незаметной тропинке сталкиваются лоб в лоб с роком - как будто торопились на свидание с ним. При этом каждый может и сам, для себя незаметно, стать посланцем рока для кого-то другого (Vološina, электронный ресурс)

- пишет Волошина в аннотации к пьесе.

Персонажей мы можем разделить на главных и второстепенных. К первой группе принадлежат Агнешка, Ион и Маша; ко второй - все остальные, 
кроме доктора Проспера, который в силу своего внесценического характера находится за рамками данного деления.

Ион Бертран - родившийся предположительно в Хорватии и выросший в Испании кинорежиссер, в клинику попадает по собственному желанию после смерти супруги и из-за усилившихся проблем с памятью. Его история составлена из выбранных эпизодов жизни Бунюэля. Бертран, например, делится с Агнешкой своими воспоминаниями, которые на самом деле взяты Волошиной из книги Бунюэля Мой последний вздох (Mon dernier soupir, 1982). Речь здесь идет, например, о длящемся целые сутки барабанном бое в Страстную Пятницу, окровавленных руках барабанщиков, выпитой в детстве дешевой водке во время вскрытия тела (у Бунюэля контекст данного воспоминания немного отличается). Побывав в клинике, Ион загорается идеей создания фильма о страхах пациентов, но из-за проблем с памятью он не в состоянии самостоятельно организовать работу. Здесь очередная точка соприкосновения с жизнью автора Призрака свободы (Le fantôme de la liberté, 1974): Бертрана, как и Бунюэля, мучает боязнь потерять память (которую они впоследствии теряют), что для обоих равно потере собственной истории и личности.

На помощь Иону приходит Маша, женщина из России, потерявшая чувство проприоцепции, т. е. ощущение положения частей тела: „Физически всё в пределах, зато в голове... Моё тело, так скажем, ослепло. В моём случае память утратило только тело. Говоря по-грубому, оно забыло, что оно есть. Что это удивительный случай - моё хорошее утешение" (Vološina 2015: 9). Передвигаясь, Маша напоминает робота, а ее речь звучит как речь иностранца. Чтобы кое-как существовать, Маше пришлось заново учиться двигаться.

Агнешка, увлекающаяся религией девушка, в детстве мечтала посвятить свою жизнь Богу и стать монахиней. Однажды, ухаживая за больным братом, мечтавшем, как и сестра, о монашеском постриге, она увидела, что ему явилась Дева Мария. Восторг и воодушевление Агнешки, однако, быстро сменились ужасом и шоком, когда на лице брата она увидела сексуальную гримасу, сопровождаемую судорогами тела:

В своём видении мой брат творил с Ней грех. (Пауза.) Я убежала, молилась всю ночь, кажется, билась в исступлении, билась головой о каменный пол... потом было несколько дней или недель беспамятства. Теперь уже он сидел у моей кровати. Он вылечился неожиданно быстро. ...Я никогда не рассказывала ему, что случилось. Тогда и началась моя болезнь. Из-за неё меня стали запирать в лечебницах - ещё Старой Европы - и обращаться со мной так, как будто я сумасшедшая и не могу сама за себя решать. Видимо, на то Его воля. Видимо, ни брат, ни я не были достойными... Я никак не чувствую свою болезнь. Совершенно никак (Vološina 2015: 27). 
Болезнь Агнешки заключается в том, что она не видит правой стороны чего-нибудь. Например, чтобы позавтракать, она вынуждена по кругу в кресле-каталке объезжать тарелку, воссоздавая правую сторону до тех пор, пока полностью не утолит голод. Или макияж: „В её случае это значит, что она красит левую половину лица, оставляя правую нетронутой” (Vološina 2015: 1-2). Первообраз болезни Агнешки описан в книге Сакса. Его пациентка „бесповоротно утратила идею «левой стороны» - как в отношении мира, так и в отношении своего собственного тела" (Saks 48). Миссис С., как и Агнешка, вынуждена была кататься вокруг еды и красить лишь половину лица. Однажды врач, используя камеру и экран, решил показать ей недостающую сторону, однако пациентка отреагировала истерикой и шоком, так как увидела то, чего в повседневной жизни даже не чувствовала. Схожий мотив камера и столкновение с пустотой - мы наблюдаем в пьесе Волошиной: свой последний фильм Ион хочет снять именно об Агнешке.

Здесь важна и вторая - бунюэлевская - религиозная составляющая данного персонажа. В ней и кроется ответ на вопрос: почему режиссер выбрал именно Агнешку? В воспоминаниях Бунюэля появляется мотив встречи с Девой Марией:

Я увидел сияющую добротой, с протянутыми ко мне руками Святую деву. Я видел ее совершенно отчетливо. Она говорила со мной, злобным атеистом, с огромной нежностью, под звуки хорошо различимой музыки Шуберта. [...] Еще не пробудившись окончательно, я продолжал шептать: „Да, да, Святая дева Мария, я верую”. [...] Добавлю, что этот сон носил несколько эротический характер. Естественно, подобная эротика ограничивалась целомудренными пределами платонической любви. Быть может, если бы сон продолжался долго, целомудрие могло исчезнуть, уступив место настоящему желанию (Bunûèl' 122).

Смирение Агнешки перед судьбой напоминает, в свою очередь, историю бунюэлевской героини Виридианы, временно ушедшей из монастыря для того, чтобы оказать помощь своему пожилому дяде. Однако тот в нее влюбляется. Не в силах удержаться, он усыпляет послушницу, пытается ее изнасиловать и, не справившись с собственными переживаниями, в итоге вешается. Узнав об этом, Виридиана решает, что отныне она недостойна жить в монастыре. Она начинает помогать малоимущим и учить их вере, но вскоре оказывается, что подопечные потешаются над ее целомудрием и ничего, кроме материальных благ, от Виридианы не ждут. Апогей разочарования бывшей послушницы приходится на кощунственную, вакханальную и подражающую Тайной вечере Леонардо да Винчи (L’Ultima Cena, 1495-1498) сцену пира бездомных. Здесь необходимо сделать небольшой экскурс в философию ХХ века. 
О категории богооставленности писал Николай Бердяев в Экзистенцииальной диалектике божественного и человеческого (1952). Богооставленность для философа означает следствие навязывания Богу понятий из мира людей. Атеизм, согласно Бердяеву, есть результат отношения к Богу как к повелителю, наводящему в своих „владениях” порядок наподобие хозяина, судящего и наказывающего провинившихся:

Нам говорили, что Бог присутствует во всем. Но присутствие Бога невозможно найти в чуме и холере, в убийствах, в ненависти и жестокости, в насилиях, в зле и тьме. Ложное учение о Промысле вело к рабьему преклонению перед силой и властью, к апофеозу успеха в этом мире, в конце концов к оправданию зла (Berdâev 259).

Рабское отношение к Богу (а следовательно, и ко всякой человеческой власти), т. е. осознание того, что человек Богу не нужен, зато Бог нужен человеку приводит к стиранию понятия свободы и любви в судьбе человека, на замену которым приходит рок:

В этом нашем мире действует не только Бог, но также рок, необходимость, случай. Рок продолжает действовать там, где мир покидает Бога и где Бог покидает мир. [...] Человек и мир подчиняются неотвратимой необходимости в результате ложно направленной свободы. Случай же, играющий огромную роль в жизни, есть как бы потерянность и беспомощность человека в множественном мире, в котором действует огромное количество неуловимых, не поддающихся рациональному учету сил. Несчастный случай, который представляется нам совершенно бессмысленным и жестоким, и означает, что мы живем в падшем мире, в котором нет Божьего управления целого. Но этот же несчастный случай может получить высший смысл в моей судьбе, внедренной в мир феноменальный. Веру в то, что все происходящее со мной имеет смысл, нельзя выразить в космологической системе, как делает теологический рационализм. Всегда нужно помнить, что Бог есть Дух, но не природа, не субстанция, не сила, не власть. Бог есть Дух, т. е. свобода (Berdâev 260).

$*$

В привязанности Агнешки к религии практически всегда присутствует страх перед всем, что выходит за узкие рамки целомудрия и послушания. Данная героиня, по сути, живет в парадигме несвободы и строгой отчетности перед высшей силой, ср.: „Грешно обманывать доктора Проспера” (Vološina 2015: 25). Власть страха над Агнешкой отмечает Ион:

У меня есть святая. Я хочу снять святую в аду. Да просто в бездне. Она же постоянно носит с собой пустоту. Она её даже не чувствует, но она про неё знает. [...] Я хорошо знаю, чего она боится. [...] Она боится увидеть отсутствие Бога. [...] Доказательство его отсутствия. Пустота. Я сниму это. [...] Святую, обреченную на муку, святую, смотрящую в бездну своего страха (Vološina 2015: 35). 
Боязнь увидеть отсутствие Бога, т. е. боязнь признаться в грандиозной ошибке, согласно Бердяеву понимаемая как незрелая или неверная форма религиозного существования, непременно приводит к воплощению предмета страха. Боязнь видеть то, что существует, присуща не одной Агнешке, а практически всем пациентам, страдавшим из-за повреждения долей мозга вследствие неких пережитых травм. Например, миссис О'Нилл убеждена в том, что она все еще молода и красива. Она неизменно ждет своего жениха, который вот-вот должен за ней приехать и увезти ее на долгожданную свадьбу. Когда ей показывают зеркало, она не верит своему отражению, испытывает шок, устраивает истерику, но вскоре обо всем забывает. Джонни, в свою очередь, не в состоянии удержать в памяти причинно-следственный контекст происходящего, поэтому его мозг, цепляясь за детали, на ходу сочиняет миркоистории, лишь бы не оказаться перед пустотой отсутствия памяти. Кроме того Джонни болезненно реагирует на изображение Христа, снятого с креста [скорее всего, речь идет о репродукции картины Ганса Гольбейна Мертвый Христос в гробу (Der Leichnam Christi im Grabe, 1521-1522)], принимая Иисуса за своего утонувшего сына. Штурмберг же, как преданный науке исследователь и экспериментатор, принимает разные препараты с целью проведения на себе неврологических опытов, но одновременно боится потерять свое „ученое” безразличие по отношению ко всему происходящему (которое впоследствии теряет). Клиника понимается Ионом как материализация ада:

ИОН. [...] Чувственность, властолюбие, жадность - три корня всех грехов. А я стал чувствовать, что корень всех грехов один. [...] Страх. Только у него множество ликов. Страх одиночества, страх никчёмности, страх забвения. Без счёта. Страх может толкнуть человека куда угодно. Страх как грех и страх как кара. Самая жестокая кара, которой можно наградить, - это воплощение страха (Vološina 2015: 14).

Среди пациентов одна лишь Мария не фокусируется на себе, но пытается провести теряющего память Иона через ,ад”. Она не дает ему погрузиться в отчаяние и безысходность. Роль Маши в пьесе отсылает к образам Беатриче и Вергилия в Божественной комедии (La Divina Commedia, 1472) - данную параллель позволяет провести указание Иона на зверей, встретившихся Данте в лесу: волчицу, льва и рысь - три символа всех грехов. Мария воспринимает свою болезнь как шанс. Она, единственная, не зацикливается на ограничениях случившейся с ней беды и пытается их преодолеть:

Так уж вышло, что я потеряла и свою жизнь и своё тело. Но так уж вышло, что у меня появились некоторые надежды. На то, что моя жизнь начнёт быть не такой уж бессмысленной, благодаря самой болезни, которая, собственно, и отняла у меня жизнь. Я непонятно 
сейчас сказала? Я имею в виду, что я совсем не какой-нибудь особенный человек. Скорей всего, у меня даже не было бы шанса хоть раз посидеть с таким известным парнем, как вы. [...] Сейчас у меня вдруг появилась маленькая возможность поучаствовать в некотором и правда важном. В некотором выходящем из обычного ряда. В некотором... как это говориться? великом (Vološina 2015: 15).

$*$

Последняя сцена - просмотр снятого Ионом день назад фильма, является конечной точкой движения действия. Ее репетицией и предвестником может считаться предпринятая Ионом попытка снять сцену о Миссис О'Нилл, во время которой героиня переживает шок от увиденного в зеркале. В случае с Агнешкой ужас охватывает всех. Для зрителя фильм скорее всего остается недоступным, но по реакциям персонажей понятно, что для Агнешки это было тяжелейшее испытание. Персонажи заговаривают на родных языках, фильм вызывает у них (впервые в пьесе) чувство сострадания. Нельзя, однако, сказать, что данная сцена полностью представляет собой удачную развязку. С одной стороны, персонажи вспоминают и сострадают Агнешке, но с другой - наконец встают лицом к лицу с одолевавшими их предметами собственных же страхов. Последняя сцена - сгусток противоречий, усложняющий ответ на вопрос о целесообразности и нравственности содеянного Ионом и Машей. Это характерный для Волошиной прием - состояние художественного мира переломить трагизмом и ощущением обреченности.

Если в Божественной комедии в аду и чистилище находятся люди грешные и не знающие Христа, то в „аду” клиники пребывают все, кто боится. И если в мире Божественной комедии порок преодолевается разумом, то в мире нарушенной нормы страх может быть побежден уже не разумом, породившим отрицание божественного, а попыткой обретения свободы. Разум же в виде отнюдь не „чистой”, но ограниченной и подвластной ощущению страха структуры порождает приспособленческую рационализацию и смирение с судьбой (Штурм, Агнешка), хотя, по всей вероятности, доктор Проспер вовсе не озабочен здоровьем своих пациентов:

МАША. [...] Джонни не симулянт. А знаете, кем он пречасто называет доктора Проспеpa? Мясником! зацепляясь за его халат. И удивляется, что халат сегодня такой чистый... В каком-то смысле он не так уж далёк от истины..

ИОН. Вы не любите врачей?

МАША. А вы любите тюремщиков? (Vološina 2015: 11)

Главврача, если верить словам Маши, скорее всего интересует его собственный успех: „Да, как видите, они бывают очень разнообразны. И здесь 
собран хороший ассортимент. У доктора Проспера выйдет добрая диссертация. «Добрая диссертация» - так можно сказать?” (Vološina 2015: 8).

Тематика Пациентов, т. е. страх и свобода, ставит пьесу в ряд текстов Волошиной, посвященных общественной и политической ситуации в России. Агнешка - казалось бы, чистейшее создание и горячая последовательница всех религиозных и поведенческих правил - оказывается в аду, так как она закрывается в клетке собственной чистоты и неучастия. Последнее очень хорошо видно в сцене чтения Ионом своих, зачастую неприличных воспоминаний: Агнешка в ответ крестится, одергивает режиссера и не желает слушать. Жизнь проходит мимо нее. Героиня не вступает в борьбу за здоровье, убегает от правды о себе и довольствуется протезом - коляской, тем самым ставя себя в прямую противоположность Маше. Как кажется, Волошина идет здесь по пути Бердяева: не обещает чудесной перемены обстоятельств и сказочной свободы от законов материи, но акцентирует отношение человека к тому, что его окружает.

Учитывая общественно-политическую логику более поздних пьес Волошиной Мама, Человек из рыбы и Дания тюрьма (см. Tyczko), можно утверждать, что в Пациентах драматург указывает на страх как на источник порочности общественного сознания. Волошина, хотя и собрала в пьесе многонациональный коллектив, приблизившись в какой-то мере к Волшебной горе Томаса Манна (Der Zauberberg, 1924), на самом деле поднимает вопрос, характерный для постсоветского пространства: персонажи „волей или неволей прячутся от себя и своей судьбы”, но драматург железной рукой ведет их навстречу судьбе. Уход от действия станет темой также более поздней пьесы Волошиной - Человек из рыбы, фрагментарно опубликованной в журнале „Teatr” (Wołoszyna).

\section{Библиография}

Berdâev, Nikolaj. Èkzistencial'naâ dialektika božestvennogo i čelovečeskogo. Moskva, Respublika, 1993. Web. 01.10.2019. yakov.works/library/02_b/berdyaev/1944_041_1.htm\#I.

Bunûèl', Luis. Moj poslednij vzdoh. Per. Aleksandra Braginskogo, Tamary Zločevskoj, Natal'i Nusinovoj. Moskva, Raduga, 1989.

Morawiec, Edmund. Wybrane filozoficzne koncepcje rozumu ludzkiego i racjonalność. Stare Kościeliska, Wydawnictwo Liberi Libri, 2014.

Saks, Oliver. Čelovek, kotoryj prinâl ženu za šlâpu i drugie istorii iz vračebnoj praktiki. Per. Grigoriâ Hasina, Ûlii Čislenko. Sankt-Peterburg, Science Press, 2006. Web. 01.10.2019. yanko.lib. ru/books/psycho/saxs=hat.pdf. 
Tyczko, Krzysztof. „Wolność i tragizm w twórczości Asi Wołoszyny”. Maski wolności w dramacie i teatrze XX $i$ XXI wieku. Red. Lidia Mięsowska, Paulina Charko-Klekot, Anna Tyka. Katowice, Wydawnictwo Naukowe „Śląsk”, 2019, s. 295-313.

Vološina, Asâ. Pacienty. 2015. Web. 01.10.2019. mythos.spb.ru/?p=19.

Vološina, Asâ. Pacienty, annotaciâ. Web. 01.10.2019. www.theatre-library.ru/authors/v/voloshina_asya.

Wołoszyna, Asia. „Człowiek z ryby. Sztuka bez ścian”, fragmenty. Przeł. Krzysztof Tyczko. Teatr, nr 12, 2018, s. 80-82. 